\title{
Energy performance for residential building - comparison between theoretical method and real measurements
}

\author{
Matgorzata Basińska ${ }^{1}$, Katarzyna Ratajczak ${ }^{1, *}$, and Jan Tomczyk ${ }^{2}$ \\ ${ }^{1}$ Poznan University of Technology, Faculty of Civil and Environmental Engineering, \\ Institute of Environmental Engineering, 4 Berdychowo St., 60-965 Poznan, Poland \\ ${ }^{2}$ TKT Engineering, 6 Karpia St., 61-619 Poznan, Poland
}

\begin{abstract}
This paper presents an energy performance of residential building (two - family building) located in Poznan. Both apartments were analysed separately. By using a method of energy performance calculations valid in Poland, a theoretical energy performance had been prepared. The calculations were conducted assuming real changeability of climatic data in years: 2010-2017. The real energy performance was prepared based on actual gas consumption for the purpose of heating and domestic hot water preparation (DHW) within the years of measurements taken, being a subject of analysis. The findings from this study revealed that a theoretical energy performance significantly deviates from the results obtained by means of energy consumption measurements, which resulted from variability of basic climatic data over time and also from theoretical usage profile of the apartments.
\end{abstract}

\section{Introduction}

Recently, a number of modifications were introduced to the Polish standards regarding energy, environment and building law in order to improve buildings' energy efficiency. A main goal is to support the dispersed energy sources, high-efficiency cogeneration and decrease of energy demand in building industry. A goal of energy efficiency law [1] adopted in May 2016 was to intensify the projects supporting improvement of energy efficiency within three areas:

- energy savings obtained by final receivers,

- increase of energy savings during its production,

- decreasing the losses during transport and distribution of gas, heat and electric energy.

In accordance with the law regarding energy performance [2] and its implementing act [3] there is a possibility to evaluate a building in regards to energy used in it, over a period of one month only. This method/approach allows comparing two buildings, taking into account the same assumptions regarding the climatic data and usage profile. The method is employed to compare the thermal properties of a building and its technical equipment with

\footnotetext{
* Corresponding author: katarzyna.m.ratajczak@put.poznan.pl
} 
the properties of a referenced building. According to the Ordinance [4] all buildings being designed presently have to meet requirements connected with:

- the value of primary energy ratio (PER),

- the value of heat transfer coefficients for walls,

- protecting of overheating during summer,

- level of the thermal insulation of the distribution pipework (ducts).

The calculations presented in this paper refer to two apartments, located in one building, with similar usable area and comparable parameters of the external walls; results will be presented in order to indicate the differences in values obtained with theoretical method of calculating energy performance of a building and with method using real measurements. The analyses were carried out assuming the changeability of climatic data within the period of time from 2010 to 2017. Due to the initial assumptions (climatic data, usage profile) the theoretical calculation results depart significantly from the real data regarding the energy consumption in the building.

\subsection{Used method}

\subsubsection{Theoretical energy performance}

Calculation of theoretical energy performance was carried out according to the methodology presented in the Ordinance regarding energy performance calculations [3]. This method is based on monthly energy readings taking into account the heat losses resulting from transfer and ventilation, but also considering the solar and indoor heat gains. Analysis includes a coefficient of heat gain usage effectiveness.

Range of calculation includes the following:

- demands for usable energy for heating and cooling,

- demands for energy supplying the technical systems of a building for the purposes of HVAC and domestic hot water preparation (DHW),

- demands for non-renewable primary energy determined using the coefficients of nonrenewable primary energy input $\mathrm{w}_{\mathrm{i}}$ for production and delivery of energy carrier or energy itself to the buildings.

\subsubsection{Real, measurements performance}

Evaluation of heating demand in a building can be conducted based on monitoring the energy delivered to a building. For that purpose it is necessary to know at least monthly value of metered electricity energy, the number of energy sources (gas, heating oil) used in a building, indoor temperature's measurement in the premises and knowledge regarding changeability of climatic parameters over time. Energy monitoring:

- gives a possibility to determine a real demand for heating and thermal power taking into account the way of building's usage or,

- helps to define the potential thermo-insulation activities and possible effects of modernisation that can be obtained.

\subsection{Climate data used for analysis}

The calculations include the data regarding changeability of outdoor air temperature in the months of the measurement years i.e. 2010-2017. The climate data was taken by meteorological station located at Ławica, Poznan (Poland) [5]. Table 1 presents the changeability of average monthly outdoor air temperature for the particular months in the 
measurement years. Last column includes the data for typical meteorological year (TMY) in Poznan city [6].

Table 1. Average monthly outdoor temperature for measurement years 2020-2015 and monthly temperatures for typical meteorological year in Poznan $\left[{ }^{\circ} \mathrm{C}\right]$.

\begin{tabular}{|c|c|c|c|c|c|c|c|c|c|}
\hline & 2010 & 2011 & 2012 & 2013 & 2014 & 2015 & 2016 & 2017 & TMY $^{*}$ \\
\hline I & -6.4 & 0.6 & 0.7 & -2.0 & -0.9 & 1.8 & -6.8 & -2.8 & 0.2 \\
\hline II & -0.8 & -2.7 & -4.0 & 0.0 & 4.0 & 0.8 & 3.4 & 0.3 & -1.8 \\
\hline III & 3.9 & 3.7 & 6.2 & -1.8 & 7.2 & 5.1 & 3.7 & 6.5 & 2.7 \\
\hline IV & 9.1 & 12.0 & 9.6 & 8.6 & 11.1 & 8.1 & 8.9 & 7.7 & 8.3 \\
\hline V & 11.8 & 14.9 & 15.9 & 15.0 & 13.9 & 12.6 & 15.5 & 13.6 & 13.0 \\
\hline VI & 17.7 & 19.3 & 16.6 & 18.1 & 16.8 & 15.9 & 18.7 & 17.8 & 16.8 \\
\hline VII & 22.4 & 18.2 & 19.8 & 20.7 & 22.2 & 19.5 & 19.2 & 18.4 & 18.3 \\
\hline VIII & 18.9 & 19.2 & 19.2 & 19.8 & 18.1 & 22.3 & 17.8 & 18.8 & 18.4 \\
\hline IX & 12.8 & 15.6 & 14.9 & 13.2 & 15.7 & 15.1 & 16.9 & 13.5 & 13.5 \\
\hline X & 6.8 & 9.9 & 8.7 & 10.8 & 11.2 & 8.0 & 8.0 & 10.7 & 7.0 \\
\hline XI & 5.0 & 4.0 & 5.6 & 5.4 & 6.0 & 5.7 & 2.6 & 4.9 & 2.2 \\
\hline XII & -5.3 & 3.7 & -1.1 & 3.1 & 2.1 & 5.5 & 1.3 & 2.2 & -0.1 \\
\hline
\end{tabular}

* TMY - typical meteorological year, data obtained from Ministry of Infrastructure website consisting the information regarding typical meteorological years and statistic climatic data used for building's energy calculations.

Due to a lack of the detailed measurements regarding solar radiation intensity for all calculations the data were used regarding the values of solar radiation intensity in typical meteorological year for Poznan actinometrical station [6].

\section{Description of analysed building}

The calculations and measurements were carried out for two apartments located in one of the semi-detached house (apartment A and apartment B). Building's shape is rectangular. The building was built in 1978-1980 using a traditional technology.

In apartment $\mathbf{A} 2$ adults (23 and 57 years old) are living. In apartment $\mathbf{B}$ two adults were living until September 2011 (both 30 years old). Since September 2011 there were two adults and a child, then since October 2015 - 2 adults and 2 children.

Table 2 presents the comparison of the areas, volumes of the analysed building including division for the separate apartments.

Table 2. Comparison of area and volume of analysed apartments in building.

\begin{tabular}{|c|c|c|c|}
\hline & unit & Apartment A & Apartment B \\
\hline usable area & $\mathrm{m}^{2}$ & 109.7 & 122.5 \\
\hline volume & $\mathrm{m}^{3}$ & 266 & 320 \\
\hline
\end{tabular}

For a purpose of this paper a detailed on-site verification was carried out in the building; the inventory of the building, its systems and the data were collected during the interviews with the inhabitants regarding an actual energy consumption, based on the inhabitants preferences referring the daily, typical usage of the devices and premises (e.g.: standard time of staying at home, optimal indoor temperature in the premises, washer or washing machine usage frequency etc.). 


\subsection{Construction characteristics}

The external walls do not meet the valid regulations regarding the building's thermal protection [4]. Eastern and western facades are not correctly insulated - only at the ground floor there is an old insulation made of Styrofoam panels $6 \mathrm{~cm}$ thick, the remaining part of the facades has no thermal insulation. The southern façade is also insulated by Styrofoam panels $6 \mathrm{~cm}$ thick, installed a long time ago. In figure 1 the views of the particular building's facades are presented.

a)

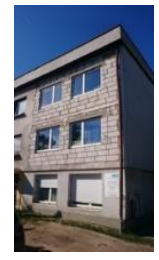

b)

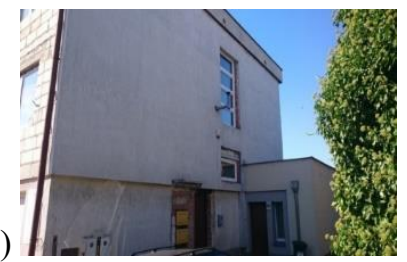

c)

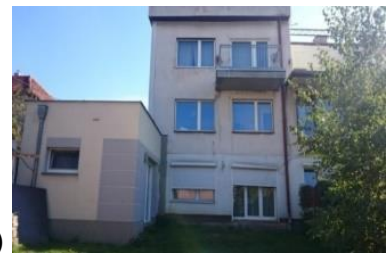

Fig. 1. Building's elevations: a) east, b) north, c) west.

Air tightness coefficient $\left(\mathrm{n}_{50}, \mathrm{~h}^{-1}\right)$ for apartment $\mathbf{A}$, during usage, is $4.79 \mathrm{~h}^{-1}$, while for apartment $\mathbf{B}-5.34 \mathrm{~h}^{-1}$. In apartment $\mathbf{A}$ coefficient is lower because only one small part of the wall at western façade is not plastered. This apartment is enlarged by additional part built in 2007 - well insulated and plastered.

\subsection{Characteristics of building's technical equipment}

A heat source for heating and DHW preparation for each of apartments (apartment A, apartment B) are combi gas condensing boilers with sealed chambers. Heating system pipework is placed in the floor, starting from the heat source. The panel radiators, equipped with the thermostatic valves, were applied. There is natural ventilation in the building.

\section{Theoretical energy performance of the building}

Theoretical characteristics include the calculations regarding the usable and final energy for a purpose of the heating and ventilation as well as DHW preparation. The analysis includes the provisions of the Ordinance regarding energy performance certificates [3]. The calculations were carried out for the alternatively variable climatic data regarding the analysed measurement years (2010-2017), which were compared with the results utilizing the average climatic data for the last 30 years (TMY).

\subsection{Usable energy}

Usable energy for heating and ventilation purpose $\mathrm{Q}_{\mathrm{H}, \mathrm{nd}}$ was calculated assuming that:

- indoor temperature is $+22^{\circ} \mathrm{C}$ (coming from measurement),

- unit heat capacity is at level of $400000 \mathrm{~J} \cdot \mathrm{K}^{-1} \cdot \mathrm{m}^{-2}$,

- internal heat gains are at level of $3.0 \mathrm{~W} \cdot \mathrm{m}^{-2}$,

- shading of building is not taking into account in heat gains coming from sun (eastern and western facades are not shaded by the other buildings etc.).

Usable energy for purpose of DHW preparation $\mathrm{Q}_{\mathrm{W}, \mathrm{nd}}$ was calculated, assuming the unit consumption of hot water equal of $35 \mathrm{dm}^{3}$.person ${ }^{-1} \cdot$ day $^{-1}$ [7]. In the new methodology for calculating building energy performance [3], the values of energy consumption for the 
domestic hot water preparation are related to the apartment's usable area. According to the authors, this method does not correspond to the profile of the apartments' use.

In figures 2 and 3 a changeability of usable energy in the measurement years (including a division for the particular purposes) is presented.

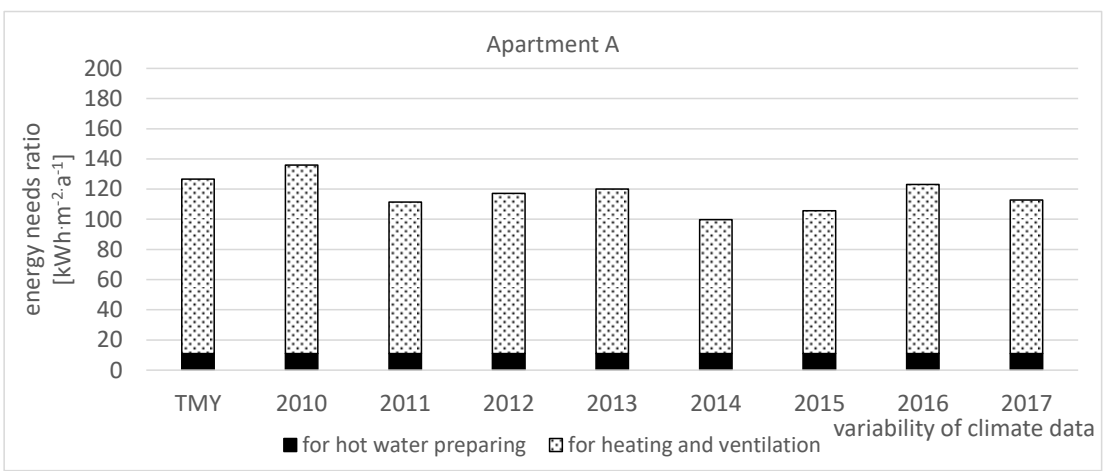

Fig. 2. Variability of usable energy - division for the particular purposes within the measurement time (years) for apartment A.

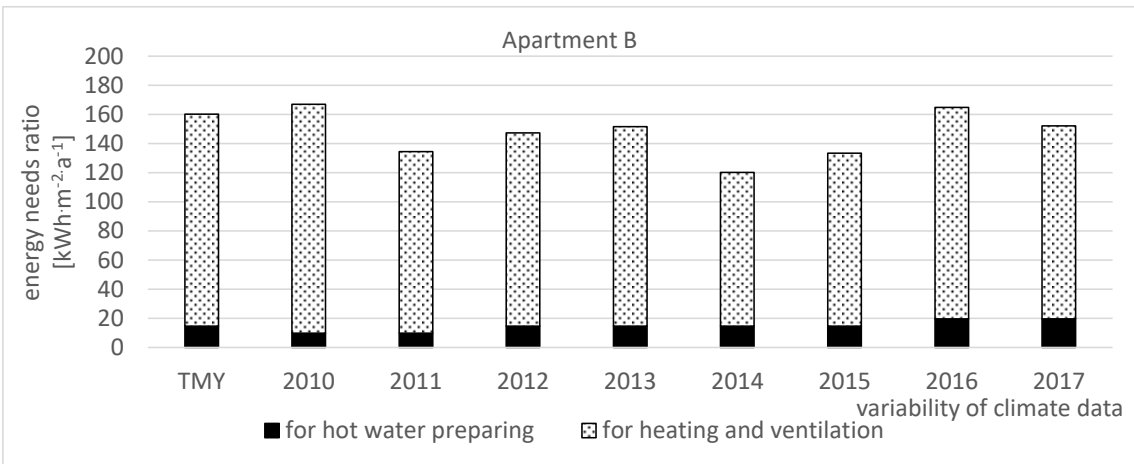

Fig. 3. Variability of usable energy - division for the particular purposes within the measurement time (years) for apartment B.

Depending on the variability of the used climatic data over time a value of usable energy for heating and ventilation changes - from 89 to $125 \mathrm{kWh} \cdot \mathrm{m}^{-2} \cdot \mathrm{a}^{-1}$ in a case of apartment $\mathbf{A}$ and from 105 to $157 \mathrm{kWh} \cdot \mathrm{m}^{-2} \mathrm{a}^{-1}$ in apartment $\mathbf{B}$. Taking the climatic data for eight years as a starting point - a value of the usable energy is reaching level of $116 \mathrm{kWh} \cdot \mathrm{m}^{-2} \cdot \mathrm{a}^{-1}$ for apartment $\mathbf{A}$ (value higher by $23 \%$ from minimum value and lower by $8 \%$ from maximum value); while for apartment $\mathbf{B}-145 \mathrm{kWh} \cdot \mathrm{m}^{-2} \cdot \mathrm{a}^{-1}$ (value lower by $8 \%$ from maximum value and higher by $27 \%$ from minimum value). The proportion between the analysed goals is also a subject of a change. A share of usable energy for DHW preparation is $10 \%$ of total usable energy.

\subsection{Final energy}

After on-site verification and inventory for both apartments, the final energy was established, assuming efficiency value, according to Table 3.

Table 3. Assumed values of efficiency of separated purposes, [\%].

\begin{tabular}{|c|c|c|c|c|}
\hline efficiency & regulation & distribution & storage & generation \\
\hline $\mathrm{H}-$ heating and ventilation & 88 & 96 & 100 & 98 \\
\hline $\mathrm{W}-$ preparation of DHW & - & 60 & 100 & 88 \\
\hline
\end{tabular}




\section{Heat consumption measurements}

The gas consumption was checked in both apartments. The readings for apartment $\mathbf{A}$ were taken every second month, while in apartment $\mathbf{B}$ monthly. In order to divide the gas consumption during a winter for heating and DHW purposes - for DHW it was assumed the average values of gas consumption during summer (June-August). There are no gas stoves in the building. For example, for apartment $\mathbf{B}$ a gas consumption for DHW depending on a number of the inhabitants and calculations method was presented in Figure 4.

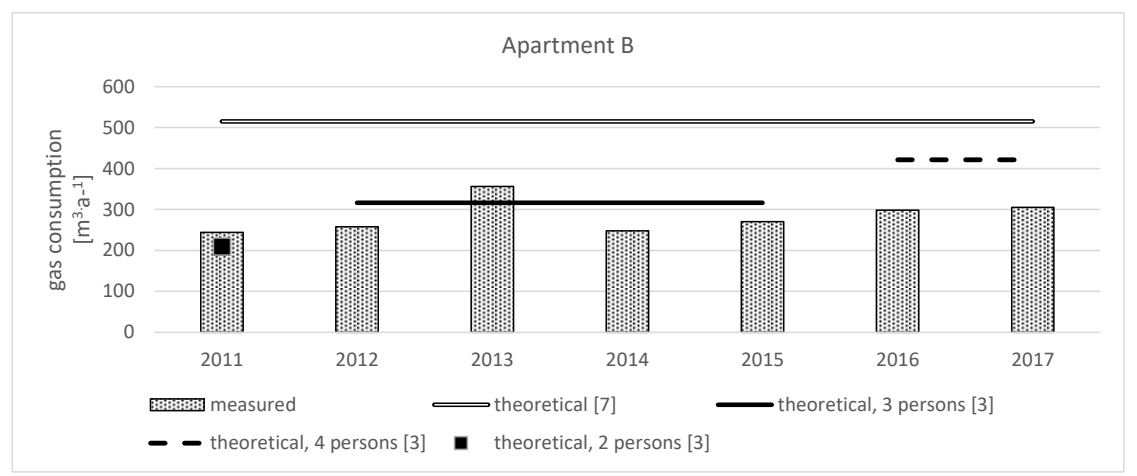

Fig. 4. Gas consumption for DHW in apartment $\mathbf{B}$.

For a purpose of a comparison the results of theoretical calculation of usable energy for DHW preparation were presented according to two different orders regarding building's energy performance [3,7]. Figure 3 presents the significant discrepancy in the obtained results of daily DHW demand, assumed for calculation, in reference to the usable area. Calculations include heating value of gas at a level of $36.3 \mathrm{MJ} \cdot \mathrm{m}^{-3}$.

Within the analysed years the starts and completions of given season were always noted. A length of heating season was variable: from 178 to 222 days.

Having the gas consumption results (for heating, ventilation and DHW purposes) from a period of 3 subsequent years, according to Ordinance requirements [3], the total value of final and primary energy ratio can be defined. Figure 5 indicates values which were compared with the presently valid thermal requirements for residential buildings [4]. None of the analysed apartments meet the presently valid thermal requirements.

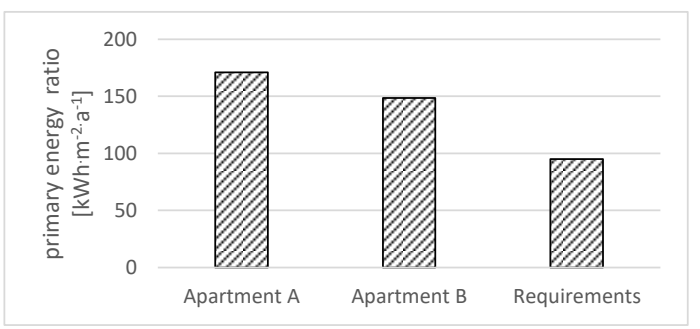

Fig. 5. Comparison of primary energy ratio appointed by actual usage method with requirements regarding building's thermal protection.

\section{Comparative analysis}

The figures 6 and 7 present a comparison of the results regarding final energy ratio for heating, ventilation and DHW, according to theoretical and real characteristics. 


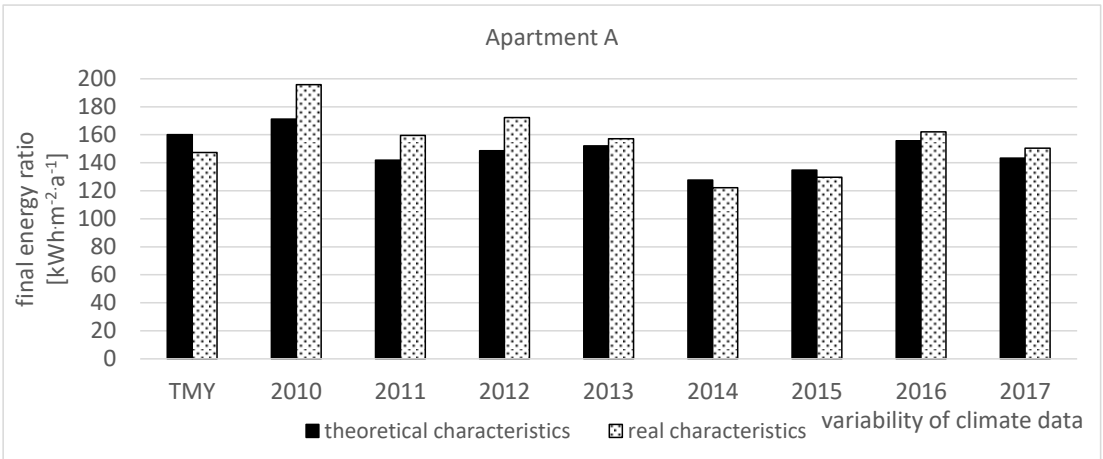

Fig. 6. Changeability of final energy within the measurement years for apartment A.

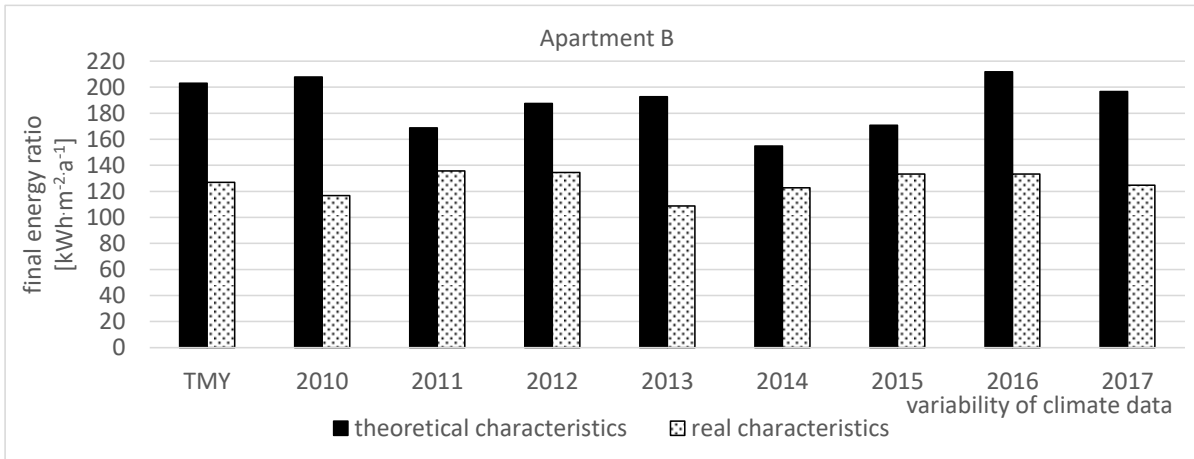

Fig. 7. Changeability of final energy within the measurement years for apartment B.

Depends on the used method and the changeability of climatic data the value of final energy changes from 128 to $171 \mathrm{kWh} \cdot \mathrm{m}^{-2} \cdot \mathrm{a}^{-1}$ for apartment $\mathbf{A}$ and for apartment $\mathbf{B} 155$ to 212 $\mathrm{kWh} \cdot \mathrm{m}^{-2} \cdot \mathrm{a}^{-1}$. In case of apartment $\mathbf{A}$ for almost all of analysed measurement years the results according to actual usage are higher than theoretical calculation values. It is opposite in case of apartment B. Assuming the real climatic data for calculation purpose the average percentage discrepancy of theoretical and real characteristics in relation to value of theoretical characteristics is $+8 \%$ for both apartments. Higher discrepancies were obtained when the average values from the period of 30 years (TMY) were assumed. For apartment A: $8 \%$, for apartment $\mathbf{B}:+37 \%$. The presented results indicate that the energy assessment of a building depends on many factors: the method and used assumptions. The way of exploitation of the apartment is very important, as shown by comparing results obtained for apartment $\mathbf{A}$ and apartment $\mathbf{B}$. Therefore, the method based on real measurements of energy consumption should be used for existing buildings.

\section{Summary}

Based on the above analyses the following conclusions can be presented:

- Results obtained by means of theoretical method, despite the assumption of the same changeability of climatic parameters, vary significantly from the real energy consumption in the apartments.

- Values of external temperature, assumed in calculations, have a significant influence on the results reg. energy demand in the building.

- Energy performance evaluation of the existing buildings is more precise when monitoring of energy supply to the building is used. 
- Hot water consumption, according to the Ordinance regulations energy performance certificates is assumed at a level of two times higher than the real measurements in the analysed apartment.

- Volume of final energy consumed by the building depends on the inhabitants' awareness (skilled control of temperature inside or way of airing the premises).

- High awareness of inhabitants can help to decrease significantly the building's exploitation costs. Theoretical method does not include an individual approach to thermal comfort of the users. The difference between indoor temperatures for the different users can vary even by a few degrees, which has a direct impact on the consumed volume of energy for heating purpose.

In the analysed building thermo-modernization improvements are planned. After their execution, it will be necessary to carry out further measurements and analyzes related to energy consumption for heating, ventilation and domestic hot water preparation. With the improvement of thermal insulation of building walls and / or improvement of air flow, a greater impact of the use of individual dwellings on the energy consumption will probably be noticeable.

The work discussed the methodology for energy performance calculations applicable in Poland with the references to standards and regulations used in that country. In further works the topic will be developed based on methodologies applicable in other countries.

\section{References}

1. Act dated $20^{\text {th }}$ of May 2016 reg. Energy efficiency, Journal of Laws 2016 item 831, (in polish), website: www.prawo.sejm.gov.pl/isap.nsf/DocDetails.xsp?id=WDU20160000831, (30.01.2018)

2. Act dated $29^{\text {th }}$ of August 2014 reg. Building Energy Performance, Consolidation, Journal of Laws 2017 item 1498, (in polish), website:

www.prawo.sejm.gov.p1/isap.nsf/DocDetails.xsp?id=WDU20170001498,(30.01.2018)

3. Ordinance of Minister of Infrastructure and Development dated $27^{\text {th }}$ of February 2015 reg. Methodology of building or its part energy performance indication and energy performance certificates, Journal of Laws 2015 item 376 and its subsequent amendments, (in polish), website:

Www.prawo.sejm.gov.pl/isap.nsf/DocDetails.xsp?id=WDU20150000376, (30.01.2018)

4. Ordinance of Minister of Infrastructure dated 12 th of April 2002 reg. Technical conditions of the buildings and its locations, Journal of laws 2015 item 1422 and its subsequent amendments, (in polish),

website: www.prawo.sejm.gov.pl/isap.nsf/DocDetails.xsp?id=WDU20150001422,(30.01.2018)

5. Climatic data, Poznan- Ławica, website: www.wunderground.com/history/airport/EPPO, (30.01.2018)

6. Typical meteorological and statistical years, website: www.mir.gov.pl, (30.01.2018)

7. Ordinance of Minister of Infrastructure dated $06^{\text {th }}$ of November 2008 reg. Methodology for calculating the energy performance of a building and a dwelling or a part of a building constituting an independent technical and functional unit as well as the method of energy performance certificates, Journal of laws 2008 no. 201, item 1240, (in polish), website: www.prawo.sejm.gov.pl/isap.nsf/DocDetails.xsp?id=WDU20082011240, (30.01.2018) 